\title{
The Perspective of Gozitan Teachers on Factors Affecting Students' Achievement
}

\author{
Lorna Xuereb ${ }^{1}$, Katya Sarah De Giovanni ${ }^{2}$ \\ ${ }^{1}$ Education Directorate, University of Malta, Beltissebh, Floriana, Malta \\ ${ }^{2}$ Department of Psychology, University of Malta, Malta \\ Correspondence: Katya Sarah De Giovanni, Department of Psychology, University of Malta, Malta.
}

Received: September 2, 2016

Accepted: November 4, $2016 \quad$ Online Published: November 10, 2016

doi:10.11114/jets.v4i12.1856

URL: http://dx.doi.org/10.11114/jets.v4i12.1856

\begin{abstract}
This study aims at exploring the impact of factors at pupil, teacher and school levels on students' academic achievement. Moreover, the main purpose was that of investigating which one of the three levels is most likely to affect students' educational accomplishment. A questionnaire was administered to 100 Gozitan teachers. Results were analysed through the independent-samples t-test and one-way ANOVA. The outcomes of the study showed that all of the presented factors tend to make an impact on students' academic attainment. However, results showed that $49 \%$ of participants chose the student level, $31 \%$ chose the teacher level and 20\% chose the school level.
\end{abstract}

Keywords: student variables, teacher variables, school variables, students' achievement, teachers' perspectives, small Island State

\section{Introduction}

\subsection{Main aim of the Study}

The main focus of this research study is that of answering the research question: 'From the perspective of Gozitan teachers, which are the main factors affecting students' achievement?' Gozo belongs to the Maltese Archipelago of Islands. Most Gozitan teachers read for an undergraduate degree at the University of Malta specialising in Education and operate under the same educational system which requires two years of supervised practiced for newly qualified teachers in order to attain professional status. This is more or less the same system which is in operation in the United Kingdom.

The study aims at discovering which of the three variables: student, teacher and school is most likely to impact students' educational achievement. The reason why the study is based on teachers' perspectives is because they are the frontliners in the education of primary school pupils. This research aims at finding out how aware they are about aspects of the students' personal lives, characteristics of teachers and school features and how they can impact academic achievement.

\subsection{Conceptual Framework}

For many years, research has investigated several factors which directly contribute to students' academic performance, for instance Farooq, Chaudhry, Shafiq and Berhanu (2011), identified four "inside and outside school" (p. 2) factors which may relate to the learners' educational achievement, namely student, family, school and peer variables. This is markedly sustained by Mlambo (2011), who asserts that the combination of family, academic and student factors, specifically parents, teachers and students, can account for a change in the students' attainment at school. With special reference to this research study, the focus is on three main factors which underlie the student variables, the teacher variables and the school variables

Marzano (2003) stated that the most significant factors affecting students' academic achievement has always been the background characteristics of students. Similarly, Jones and Zambone (2009) declare that "... a supportive home environment; learned intelligence; and sufficient background knowledge and experience" (p.236) are dynamics which fall under the student level. Contrary to this, McCoach, Goldstein, Behuniak, Reis, Black, Sullivan and Rambo (2010) regarded characteristics related to the learners' background, such as language, socioeconomic status and ethnicity as predictors of academic achievement. In this particular research study, the main factors at student level include social background, socioeconomic status and parental involvement. 
Phillipson, Ku and Phillipson (2013), regarded teachers as having an essential role in the shaping of the social environment where learners are educated and are also viewed as playing a crucial part in providing students with the necessary aid and guidance. In fact, they declare that “... how the teachers understand and go about learning, how teachers and students relate to each other, and how teachers challenge and guide learning are all powerful factors in academic performance" (p. 46). In this particular research study, the main factors at teacher level include teachers' professional development, teaching experience, teacher behaviours as well as teacher-student relationships.

As stressed by Muijs, Harris, Chapman, Stoll and Russ (2004) "a focus on teaching and learning, effective distributed leadership, creating an information-rich environment, creating positive school culture, creating a learning environment and a strong emphasis on continuous professional development" (p. 149) are all factors at school level which are considered as vital for schools in order to be fully improved as well as effective. A similar research study carried out by Sammons (1999), identified several school-level factors, some of which include having a professional leader, a mutual vision and objectives, focusing on educating and learning, a partnering home and school and also monitoring improvement. In this particular research study, the main factors at school level include the school ethos, school climate, school organisation and the school curriculum.

However, perhaps one of the most important studies is the one by Hattie (2009) who identified 195 influences and effect sizes in relation to student achievement. The six areas that Hattie identified are the student, the home, the school, the curricula, the teacher, and teaching and learning approaches. His research was updated to 195 effects in 2015 and is now based on 1200 meta-analyses when compared to the 800 studies under review in 2009. Hattie claims that 'effect sizes' are the best way of ascertaining the greatest influence on student learning. An effect-size of 1.0 is typically associated with advancing learners' achievement by one year, or improving the rate of learning by 50\%; a correlation between some variable (e.g., amount of homework) and achievement of approximately .50 and a two-grade leap in GCSE, e.g. from a C to an A grade. The highest effect which, according to Hattie is a teacher variable, is that of feedback with an effect size of 1.13. Hattie has made clear that 'feedback' includes telling students what they have done well and what they need to do to improve such as corrective work and the of setting targets. However, it also includes clarifying goals such as giving students assessment criteria for example which would be included in 'feedback'. As well as feedback on the task Hattie believes that students can get feedback on the processes they have used to complete the task, and on their ability to self-regulate their own learning. The second highest effect (1.04) is student's prior cognitive ability which refers to measures of intelligent quotient and other similar measures. This is followed by instructional quality (1.00), also a teacher variable, which is the student's view of teaching quality as found mainly in Higher Education institutions and colleges. The fourth effect in rank order is instructional quality (0.82), also a teacher variable, which refers to the number of hours of instruction that the student receives. This refers to direct instruction where there is active learning in class and the student's work is marked in class with corrective work which is carried out. The teacher then reviews learning after one hour, five hours and 20 hours of study.

The literature does not really provide any data with regards to differences in teachers' ages and their gender in relation to what they think affects student achievement. For this reason, this study is rather innovative by taking this direction of this research and might have also implications on initial and continuing teacher training.

The approach which will be taken so as to identify which factors according to Gozitan teachers, tend to affect students' academic achievement. A questionnaire containing several questions about the topic was administered. Next, these responses will be analysed through a number of statistical techniques including an independent-samples t-test and the one-way ANOVA.

The research question for this study is thus as follows:

From the perspective of Gozitan teachers, which are the main factors affecting students' achievement?

What differences are there in relation to age and gender of Gozitan teachers, on the factors affecting student achievement?

\section{Method}

In this section, a brief explanation of the study's research methodology is provided, including details about the research method, participants, the data collection, the data analysis and also ethical implications.

\subsection{Research Method}

In this dissertation, a quantitative data collection was utilised, which according to Muijs (2004), is fundamentally about the collection of figures to elucidate a specific question or phenomenon. The main research tool which was used in this study was that of questionnaires, which Brown (2001) describes as “... any written instruments that present respondents with a series of questions or statements to which they are to react either by writing out their answers or selecting from among existing answers" (p. 6). A reason for choosing questionnaires was that they are regarded as a 
simple and fast method of collecting data from participants (Wilson, 2013). Furthermore, when compared to other methods, they save time, are quite simple to analyse and respondents can be given a suitable time frame to answer the questions (Gillham, 2007). It also enables to get a very good sample given the small population size of students attending primary schools in Gozo, namely 1448 enabling almost total participation. Almost the entire population is female and this is also reflected in the sample with $88 \%$ being female and $12 \%$ being male. Teachers were recruited after permission was attained from the Department of Quality and Standards in Education within the Ministry of Education in Malta.

The main language used in the questionnaire was English. Additionally, most of the questions were closed-ended with the use of a Likert Scale and only a few of them were open-ended. The questionnaire was organised in four sections based on the literature review which was conducted. In the first part, participants were required to fill in their personal information, including their age, gender, present teaching post and also the number of years they have been teaching at a primary school. Following this was a section on the student level, which included questions about students' social background, socioeconomic status and also parental involvement, and their correlation with students' performance at school. The next section discussed factors at teacher level, mainly teachers' professional development, teacher experiences, teacher behaviours as well as teacher-student relationships and their influence on students' success. For the final section, the focus was on the school level and the underlying factors, including the school organisation, together with the school climate, ethos and curriculum and their link with students' performance at school. The questionnaire was 6 pages long.

The majority of the questions required participants to tick their reply on a Likert Scale with the following possible replies: strongly agree, agree, disagree and strongly disagree. Furthermore, there were other questions which required respondents to tick more than one answer and in other instances, they had to answer an open-ended question in the space provided. To conclude the questionnaire, they were free to write any additional comments. A copy of the questionnaire is found at the Appendix of this paper.

\subsection{Participants}

A hundred primary teachers participated in this research study, specifically those teaching in Gozitan schools. Participants range from teachers teaching in Year 1 to those teaching in Year 6. The population and sample are almost entirely female.

\subsection{Data Collection}

The respondents who participated in this research study were all given a questionnaire. Together with the questionnaire, a letter was attached explaining the aims of the study as well as a short description of the questionnaire. Permission by the Education Directorate of Malta was granted to distribute the questionnaires in a number of state schools in Gozo and all heads of school agreed on handing out the questionnaires to the teachers posted in their schools. Four weeks were allotted to the respondents to submit their replies.

\subsection{Data Analysis}

The data which was collected from the questionnaires was submitted in and processed by a statistical program entitled "Statistical Package for Social Sciences" (SPSS Version). As inferred by Illig (2011), this software was established back in 1986 by Norman H. Nie, C. Hadlai (Tex) Hull and Dale H, and aims at enabling "... fundamental data management and extensive statistic and graphic data analyses with the most used statistic methods" (p. 2). With regards to the statistical techniques, the one-way ANOVA, an independent samples t-test and a post hoc test were carried out so as to investigate significant differences between groups. Correlations will be carried out to establish relationships between variables.

\subsection{Ethical Implications}

Throughout the process of the distribution of questionnaires, a main priority was the confidentiality of the responses and the anonymity of participants. As a matter of fact, in the consent form provided to all heads of school, it was made clear that the identity of the schools and of the corresponding teachers were not to be mentioned. This was also stated in a consent form provided to all teachers who participated in this research study. Full anonymity was also indicated in the covering letter accompanying the questionnaire. This was deemed to be an issue of utmost importance since Gozo is an island with only 37,342 inhabitants (NSO, 2015).

\section{Results}

This section contains a summary of the results which were gathered from the questionnaires distributed to Gozitan teachers. 


\subsection{Factors at Student, Teacher and School Level}

Table 1. Factors at Student, Teacher and School Level

\begin{tabular}{llll}
\hline & & Frequency & Percent \\
\hline Valid & Social Background & 17 & 17.0 \\
& Socioeconomic status & 11 & 11.0 \\
& $\begin{array}{l}\text { Parental involvement } \\
\text { Teachers' }\end{array} \quad 72$ & 72.0 \\
& professional & & 6.0 \\
& 6 & 22.0 \\
& Teacher experience & 22 & 12.0 \\
Teacher behaviours & 12 & 60.0 \\
Teacher-student relationships & 60 & 18.0 \\
School organisation & 18 & 39.0 \\
School climate & 39 & 16.0 \\
School ethos & 16 & 27.0 \\
School curriculum & 27 & . \\
\hline
\end{tabular}

Table 1 illustrates in figures, Gozitan primary teachers' perspectives on the factors at student level, mainly social background, socioeconomic status and parental involvement. As can be visible in the data collected, the majority of participants, $72.0 \%$, chose parental involvement as the main variable which affects students' academic achievement. This is followed by social background with a score of $17.0 \%$ and socioeconomic status with the lowest score of $11.0 \%$. These percentages clearly show that respondents view parental involvement as the central factor at student level which influences the educational achievement of students.

Furthermore, as illustrated in the figures presented above, it is quite clear that the most popular variable at teacher level was the teacher-student relationship, scoring at $60.0 \%$. The other $40.0 \%$ were divided amongst the other factors, having $22.0 \%$ of respondents who chose teacher experience, $12.0 \%$ who marked teacher behaviours and $6.0 \%$ who selected teachers' professional development. When reflecting on these statistics, it is made evident that Gozitan primary teachers regard the relationship which is adopted between the teacher and the student as the main variable which affects students' educational performance.

School climate, which was chosen by 39 participants scored at $39.0 \%$, followed by the school curriculum which scored at $27.0 \%$. The two variables which had minimum votes were the school organisation and the school ethos, one scoring at $18.0 \%$ while the other $16.0 \%$. The data collected shows that Gozitan primary teachers regard the school climate as the chief factor at school, which makes an impact of the students' educational accomplishment.

Table 2. Factors Affecting Student Achievement

\begin{tabular}{llll}
\hline & & Frequency & Percent \\
\hline Valid & Student level & 49 & 49.0 \\
& Teacher level & 31 & 31.0 \\
& School level & 20 & 20.0 \\
& Total & 100 & 100.0 \\
\hline
\end{tabular}

Table 2 provides an insight on the perspective of Gozitan primary teachers on the three main factors which were investigated in this study, mainly the student, the teacher and the school levels. As the statistics clearly show, all three level were chosen by respondents, however the variable which was selected the most was the student level, at $49.0 \%$. This was followed by the teacher level, which scored at $31.0 \%$ and the school level which had smallest number of votes, $20.0 \%$. After choosing their preferred response, participants were asked to give a reason for their reply. This was done so that it would be easier for the researcher to understand why one variable was selected over the other two.

\subsection{Differences by Gender}

As displayed in table 3, an independent-samples t-test was carried out to link the above variables together with the gender. From the produced results, it was concluded that there was a significant difference by gender in only two variables, mainly social background and the school climate, with a significance of $\mathrm{P}=.013$ and the $\mathrm{P}=.017$ respectively. Given the significant results obtained, it is argued that for social background, males scored significantly higher than females. On the other hand, for the school climate, females scored significantly higher than males. With regards to the mean scores, it was quite evident that all variables had a low mean score. This means that the majority of male and female responses were "strongly agree" and "agree". Nevertheless, there were two variables which had a higher mean score than the others, namely social background and teacher experience, one with a mean score of 1.50 and the other with a score of 1.08. This means that responses varied from "agree" to "disagree". The effect sizes (Cohen's d) for the items on which a significant difference was calculated were 0.94 for social background and 0.74 for school climate. This means that the differences between means for these items had a large and medium effect respectively. 
Table 3. An Independent-Samples t-test of the Effect of Gender on the Presented Variables

\begin{tabular}{|c|c|c|c|c|c|c|c|}
\hline \multirow[t]{3}{*}{ Outcome } & \multicolumn{7}{|c|}{ Group } \\
\hline & \multicolumn{2}{|l|}{ Male } & \multicolumn{2}{|c|}{ Female } & \multirow[b]{2}{*}{$\mathrm{t}$} & \multirow[b]{2}{*}{$\mathrm{p}$} & \multirow[b]{2}{*}{$95 \% \mathrm{CI}$} \\
\hline & M & SD & M & SD & & & \\
\hline Social background & 1.50 & 0.80 & 0.94 & 0.70 & 2.54 & .013 & {$[0.12,0.99]$} \\
\hline Socioeconomic status & 0.92 & 0.67 & 0.85 & 0.64 & 0.33 & .744 & {$[-0.33,0.46]$} \\
\hline Parental involvement & 0.25 & 0.45 & 0.44 & 0.52 & -1.22 & .226 & {$[-0.51,0.12]$} \\
\hline $\begin{array}{l}\text { Teachers' professional } \\
\text { development }\end{array}$ & 0.75 & 0.45 & 0.88 & 0.58 & -0.71 & .478 & {$[-0.47,0.22]$} \\
\hline High-quality teaching & 0.33 & 0.49 & 0.53 & 0.52 & -1.25 & .213 & {$[-0.52,0.12]$} \\
\hline Teacher experience & 0.92 & 0.52 & 1.08 & 0.57 & -0.94 & .352 & {$[-0.51,0.18]$} \\
\hline Teacher behaviours & 0.67 & 0.49 & 0.55 & 0.52 & 0.76 & .450 & {$[-0.20,0.44]$} \\
\hline $\begin{array}{l}\text { Teacher-student } \\
\text { relationship }\end{array}$ & 0.83 & 0.72 & 0.73 & 0.50 & 0.66 & .514 & {$[-0.22,0.43]$} \\
\hline School organisation & 0.67 & 0.65 & 0.93 & 0.56 & -1.50 & .136 & {$[-0.62,0.09]$} \\
\hline School climate & 0.50 & 0.52 & 0.88 & 0.50 & -2.43 & .017 & {$[-0.68,-0.07]$} \\
\hline School ethos & 0.58 & 0.23 & 0.67 & 0.58 & -0.47 & .643 & {$[-0.46,0.29]$} \\
\hline School curriculum & 0.83 & 0.72 & 0.78 & 0.51 & 0.30 & .768 & {$[-0.28,0.38]$} \\
\hline
\end{tabular}

Note. Likert Scale: Strongly agree (0), agree (1), disagree (2), strongly disagree (3)

\subsection{Differences by Age}

Table 4. One-way ANOVA of the Impact of Age on the Presented Variables

\begin{tabular}{|c|c|c|c|c|c|c|}
\hline Source & & SS & df & MS & $\mathrm{F}$ & $\mathrm{p}$ \\
\hline \multirow[t]{3}{*}{ Social Background } & Between Groups & .591 & 4 & .148 & .268 & .898 \\
\hline & Within Groups & 52.399 & 95 & .552 & & \\
\hline & Total & 52.990 & 99 & & & \\
\hline \multirow[t]{3}{*}{ Socioeconomic Status } & Between Groups & 1.157 & 4 & .289 & .707 & .589 \\
\hline & Within Groups & 38.883 & 95 & .409 & & \\
\hline & Total & 40.040 & 99 & & & \\
\hline \multirow[t]{3}{*}{ Parental Involvement } & Between Groups & .587 & 4 & .147 & .541 & .706 \\
\hline & Within Groups & 25.773 & 95 & .271 & & \\
\hline & Total & 26.360 & 99 & & & \\
\hline professional & Between Groups & .942 & 4 & .236 & .719 & .581 \\
\hline \multirow[t]{2}{*}{ Development } & Within Groups & 31.098 & 95 & .327 & & \\
\hline & Total & 32.040 & 99 & & & \\
\hline \multirow[t]{3}{*}{ High-quality teaching } & Between Groups & .735 & 4 & .184 & .664 & 618 \\
\hline & Within Groups & 26.255 & 95 & .276 & & \\
\hline & Total & 26.990 & 99 & & & \\
\hline \multirow[t]{3}{*}{ Teacher experience } & Between Groups & 1.379 & 4 & .345 & 1.082 & .370 \\
\hline & Within Groups & 30.261 & 95 & .319 & & \\
\hline & Total & 31.640 & 99 & & & \\
\hline \multirow[t]{3}{*}{ Teacher behaviours } & Between Groups & .573 & 4 & .143 & .522 & .720 \\
\hline & Within Groups & 26.067 & 95 & .274 & & \\
\hline & Total & 26.640 & 99 & & & \\
\hline \multirow[t]{3}{*}{ Teacher-student relationship } & Between Groups & .303 & 4 & .076 & .267 & .898 \\
\hline & Within Groups & 26.937 & 95 & .284 & & \\
\hline & Total & 27.240 & 99 & & & \\
\hline \multirow[t]{3}{*}{ School organisation } & Between Groups & 1.865 & 4 & .466 & 1.422 & .233 \\
\hline & Within Groups & 31.135 & 95 & .328 & & \\
\hline & Total & 33.000 & 99 & & & \\
\hline \multirow[t]{3}{*}{ School climate } & Between Groups & .124 & 4 & .031 & .113 & .978 \\
\hline & Within Groups & 25.986 & 95 & .274 & & \\
\hline & Total & 26.110 & 99 & & & \\
\hline \multirow[t]{3}{*}{ School ethos } & Between Groups & .235 & 4 & .059 & .154 & .961 \\
\hline & Within Groups & 36.205 & 95 & .381 & & \\
\hline & Total & 36.440 & 99 & & & \\
\hline \multirow[t]{3}{*}{ School curriculum } & Between Groups & 2.697 & 4 & .674 & 2.473 & .050 \\
\hline & Within Groups & 25.893 & 95 & .273 & & \\
\hline & Total & 28.590 & 99 & & & \\
\hline
\end{tabular}

*. The mean difference is significant at the 0.05 level.

Table 4 represents results which were carried out by one-way ANOVA so as to test the impact of age on the items presented in the above table. An analysis of variance showed that age made a significant effect on only one variable, namely the school curriculum, which scored a significance of $F=.050$. Through this score, it would seem that the null 
hypothesis was rejected, while the alternative hypothesis was accepted, and so the mean scores were significantly different. On the other hand, the rest of the variables all scored a significance $>0.05$, and so in this case, the null hypothesis was accepted and the alternative hypothesis was rejected. These results show that the mean scores between groups were similar. Overall, the outcomes of these scores showed that the significant difference by age was a small one, since it only affected one of the presented variables. In fact since there were only two respondents in the ages bracket of 50 to 59 , the results cannot be deemed significant.

Table 5. Student-Newman-Keuls of Age on the School Curriculum

\begin{tabular}{|c|c|c|c|}
\hline \multirow{2}{*}{\multicolumn{4}{|c|}{ School curriculum }} \\
\hline & & \multicolumn{2}{|c|}{ Student-Newman-Keuls a.b } \\
\hline \multirow[b]{2}{*}{ Age } & \multirow[b]{2}{*}{$\mathrm{N}$} & \multicolumn{2}{|c|}{ Subset for alpha $=0.05$} \\
\hline & & 1 & 2 \\
\hline $50-59$ & 2 & .00 & \\
\hline $31-39$ & 29 & & .66 \\
\hline 23 & 15 & & .73 \\
\hline $40-49$ & 29 & & .86 \\
\hline $24-30$ & 25 & & .96 \\
\hline Sig. & & 1.000 & .676 \\
\hline \multicolumn{4}{|c|}{$\begin{array}{l}\text { Means for groups in homogeneous subsets are } \\
\text { displayed. } \\
\text { a. Uses Harmonic Mean Sample Size }=7.400 \text {. } \\
\text { b. The group sizes are unequal. The harmonic mean } \\
\text { of the group sizes is used. Type I error levels are not } \\
\text { guaranteed. }\end{array}$} \\
\hline
\end{tabular}

Table 5 represents the Student-Newman-Keuls post-hoc comparisons on the effect which age had on the school curriculum. According to the above output, the group of teachers which was significantly different was of ages 50-59. This means that this group thought that curriculum significantly impacted student achievement.

\section{Discussion}

\subsection{Evaluation of Results}

In summary, from the perspective of Gozitan primary teachers, out of the three levels investigated in this research study, the student level mostly influences the students' academic achievement. According to the perspective of teachers, positive environments as well as supportive parents are vital in order for students to stay focused in their school work. Moreover, students need to be willing to learn if they want to succeed, and their social background makes a significant difference in their educational achievement. This is further supported by Marzano (2003), Bugge and Wikan (2013) as well as Ker (2015), who also regarded factors at student level as affecting students' educational success the most. Nevertheless, the outcomes of this research study differ from what was established in the studies of Stronge (2010), Wright, Horn and Sanders (1997), Mohammadpour, Shekarchizadeh and Kalantarrashidi (2015) and also Moos (1979), who discovered that factors at teacher and school levels are the ones which make an impact on students' academic attainment. The study by Hattie (2009) points to feedback which is a teacher variable which makes the most impact on student achievement.

According to the statistical techniques used throughout the study, the independent samples t-test resulted that there was a significant difference by gender on social background and the school climate, one with a significance of $\mathrm{P}=.013$ and the other $\mathrm{P}=.017$. With regards to the mean scores, there were two variables which had a higher mean score than the others, namely social background and teacher experience, one with a mean score of 1.50 and the other with a score of 1.08. Furthermore, the one-way ANOVA resulted that there was a significant difference by age on the school curriculum, by the participants' teaching post on the school ethos and by the participants' years of experience on social background. Results on age difference cannot be deemed conclusive as the age group under consideration was too small.

\subsection{Limitations of Study}

This study was one of the first of its kind in Gozo and it contained the participation of almost the entire population of teachers working in the primary sector. It also examined differences in variables which are not usually reported on in studies on student achievement. Despite having several strengths, this research study also had several limitations. Given that the results of a quantitative research study are presented by means and percentages, responses are generalised to the whole population. This is a limitation, since responses were not as detailed and as well explained by participants. Additionally, a problem which was encountered throughout the collection of data was that since Gozitan schools are quite limited in the number of teachers employed, it was quite difficult to gather enough responses for the research study. This became even more challenging when not all questionnaires were collected, and a few of them were even returned 
incomplete. Moreover, sampling should have accounted for the different age groups in an adequate manner to enable results which were more conclusive.

\subsection{Recommendations for Future Studies}

Through the outcomes of this study, several recommendations may be pointed out. Given that according to teachers' beliefs, social background was one significant factor affecting students' performance at school, it was recommended that there should be the development of strategies which promote inclusion of students whose social demographics differ from the rest of the students in class. This seems to be a matter of concern to Gozitan teachers and requires further investigation perhaps through qualitative, in-depth research. Another factor discussed in relation to academic achievement was parental involvement, and it was recommended that first and foremost, schools should create more initiatives which would encourage parents to be more involved in their children's education, for instance planning in-class activities, inviting them to attend school outings and also encouraging them participate in school activities, such as concerts, prize days as well as volunteering and fundraising activities. Secondly, teachers should keep in contact with parents by keeping them updated about their children's educational progress.

After reviewing research on this particular topic, it was concluded that more studies should focus on this area, since it would facilitate educators' understanding of variation in students' achievement. Initially, based on the outcomes of this research study, future research should concentrate on the three underling factors at student level, namely social background, socioeconomic status as well as parental involvement, and how these might impact students' educational attainment. Nevertheless, even though the teacher and school levels were in minority, it is still suggested that studies should focus on the ways in which they might affect students' success at school. One more suggestion for future research is that since the study is based on Gozitan teachers, others studies should explore the perspective of the Maltese population as well.

\section{Acknowledgements}

The authors would like to thank all the Maltese Education Directorate for the permission to conduct this study and the Gozitan teachers who participated.

\section{References}

Brown, J. D. (2001). Using surveys in language programs. United Kingdom, UK: Cambridge University Press.

Bugge, L. S., \& Wikan, G. (2013). Student level factors influencing performance and study progress. The Online Journal of New Horizons in Education, 3(2), 30.

Constructing educational achievement: A sociocultural perspective (2013). In Phillipson S., Ku K. Y. L. and Phillipson S. N. (Eds.). London, UK; New York, NY: Routledge.

Farooq, M. S., Chaudhry, A. H., Shafiq, M., \& Berhanu, G. Factors affecting students' quality of academic performance: A case of secondary school level. Journal of Quality and Technology Management, 7(2), 1.

Gillham, B. (2007). The pros and cons of questionnaires. Developing a questionnaire (2nd ed., pp. 1). London, UK; New York, NY: Continuum International Publishing Group.

Illig, F. (2011). Statistical analysis in practice and evaluation of research results. München, Germany: Grin.

Jones, J. B., \& Zambone, A. B. (2009). The turnaround school library program. In M. Orey, V. J. McClendon \& R. M. Branch (Eds.), Educational media and technology yearbook (pp. 231). New York, NY: Springer Science+Business Media. http://dx.doi.org/10.1007/978-0-387-09675-9_16

Ker, H. W. (2015). The impacts of student-, teacher- and school-level factors on mathematics achievement: An exploratory comparative investigation of Singaporean students and the USA students. Educational Psychology. An International Journal of Experimental Educational Psychology, 36(2), 254.

Marzano, R. J. (2003b). The student-level factors. What works in schools: Translating research into action (pp. 123). Virginia, USA: Association for Supervision and Curriculum Development.

McCoach, D. B., Goldstein, J., Behuniak, P., Reis, S. M., Black, A. C., Sullivan, E. E., \& Rambo, K. (2010). Examining the unexpected: Outlier analyses of factors affecting student achievement, Journal of Advanced Academics, 21(3), 426. http://dx.doi.org/10.1177/1932202X1002100304

Mlambo, V. (2011). An analysis of some factors affecting student academic performance in an introductory biochemistry course at the University of the West Indies. Caribbean Teaching Scholar, 1(2), 79. 
Mohammadpour, E., Shekarchizadeh, A., \& Kalantarrashidi, S. A. (2015). Multilevel modeling of science achievement in the TIMSS participating countries. The Journal of Educational Research, 108(6), 449. http://dx.doi.org/10.1080/00220671.2014.917254

Moos, R. H. (1979). Evaluating educational environments. San Francisco, CA: Jossey-Bass Publishers.

Muijs, D., Harris, A., Chapman, C., Stoll, L., \& Russ, J. (2004). Improving schools in socioeconomically disadvantaged areas-A review of research evidence. School Effectiveness and School Improvement, 15(2), 149. http://dx.doi.org/10.1076/sesi.15.2.149.30433

National Statistics Office, Malta. (2015). Gozo in Figures. ISBN: 978-99957-29-56-1. https://nso.gov.mt/en/publicatons/Publications_by_Unit/Documents/02_Regional_Statistics_(Gozo_Office)/Gozo_ in_Figures_2015.pdf

Routledge. Teachers' Toolbox UK. Professor John Hattie's Table of Effect Sizes. http://www.teacherstoolbox.co.uk/T_effect_sizes.html Accessed on 4/11/2016.

Sammons, P. (1999). School effectiveness: Coming of age in the twenty-first century. The Netherlands: Swets \& Zeitlinger.

Stronge, J. H. (2010). Effective teachers = student achievement: What the research says. New York, NY:

Visible Learning. Hattie Ranking: 195 Influences and Effect Sizes Related To Student Achievement http://visible-learning.org Accessed on 4/11/2016

Wilson, C. (2013). Questionnaires and surveys. Credible checklists and quality questionnaires: A user-centered design method (pp. 29). Waltham, MA: Elsevier. http://dx.doi.org/10.1016/B978-0-12-410392-4.00002-7

Wright, S. P., Horn, S. P., \& Sanders, W. L. (1997). Teacher and classroom context effects on student achievement: Implications for teacher evaluation. Journal of Personnel Evaluation in Education, 11(1), 57. http://dx.doi.org/10.1023/A:1007999204543

This work is licensed under a Creative Commons Attribution 3.0 License. 